\title{
Sodium-Glucose Cotransporter 2 Inhibitors with Renoprotective Effects
}

\author{
Bancha Satirapoj \\ Division of Nephrology, Phramongkutklao Hospital and College of Medicine, Bangkok, Thailand
}

\section{Keywords}

Sodium-glucose cotransporter 2 inhibitors . Glycemic

control - Diabetic nephropathy - Chronic kidney disease

\begin{abstract}
Background: Diabetes is the leading cause of end-stage renal disease (ESRD) and accounts for $40-50 \%$ of patients requiring renal replacement therapy. The main pathophysiology of diabetic nephropathy comprises glucose-dependent pathways, hemodynamic pathways, and genetic factors. Summary: Glucose-dependent pathways, known as advanced glycation, polyols, and protein kinase $C$ activation have been implicated in the pathogenesis of diabetic nephropathy. Current studies have indicated that intensified glycemic control retards the rate of development of albuminuria and impairs renal function in both patients with type 1 and 2 diabetes. However, therapeutic options have substantially increased over the last decade, but have not yet been translated to remarkably reduce the incidence of ESRD from diabetic nephropathy. Sodium-glucose cotransporter 2 (SGLT2) inhibitors are a novel class of glucose-lowering agents with potential renoprotective effects. Key Message: SGLT2 inhibitors represent a promising therapeutic approach to prevent and improve nephropathy among pa-
\end{abstract}

\section{KARGER}

(C) 2017 S. Karger AG, Basel

E-Mail karger@karger.com

www.karger.com/kdd tients with type 2 diabetes. The current data strongly support that SGLT2 inhibitors have renoprotective properties not only by improving glycemic control but also through hemodynamic and nonhemodynamic renal effects. This review focuses on the latest published data dealing with hypoglycemic agents and SGLT2 inhibitors regarding the progression of kidney disease.

\footnotetext{
(c) 2017 S. Karger AG, Basel
}

\section{Introduction}

Typical diabetic nephropathy was first described as nodular glomerulosclerosis associated with proteinuria and hypertension by Kimmelstiel and Wilson. Diabetic nephropathy is the leading cause of end-stage renal disease (ESRD) in the world [1]. The prevalence of renal complications accounts for $30-50 \%$ of patients with type 1 and 2 diabetes. Nephropathy remains a major cause of morbidity and mortality for diabetic patients, mostly from cardiovascular complications [2]. Current treatments to prevent nephropathy and slow its progression, based on glycemic and hypertensive control with reninangiotensin aldosterone system (RAAS) inhibition, are only partially effective, and a residual risk to develop

Bancha Satirapoj

315, Division of Nephrology, Department of Medicine Phramongkutklao Hospital and College of Medicine

Bangkok 10400 (Thailand)

E-Mail satirapoj@yahoo.com 
ESRD still remains. Thus, new therapeutic approaches including novel antiglycemic agents leading to additional risk reduction are needed.

\section{Glucose-Dependent Pathways Leading to Nephropathy}

The pathophysiology of diabetic nephropathy comprises glucose-dependent pathways, hemodynamic pathways, and various genetic factors that determine susceptibility and progression to ESRD [3, 4]. A major risk factor for the microvascular complications of diabetes is chronic high blood glucose levels. The facilitative glucose transporter GLUT1 mediates mesangial cell glucose flux, leading to the activation of signaling cascades, mesangial cell and matrix formation and an intrinsic pathway of proapoptotic signaling [5] favoring glomerulosclerosis [6]. Hyperglycemia-induced cell signaling, known as advanced glycation, polyols, and protein kinase $\mathrm{C}$ activation have been implicated in the pathogenesis and determine the progression of diabetic nephropathy. These pathways ultimately lead to increased renal albumin permeability and extracellular matrix accumulation, resulting in increasing proteinuria, glomerulosclerosis and ultimately renal fibrosis.

RAAS activation induces vasoconstriction and antinatriuresis, and promotes cell proliferation, apoptosis, and differentiation as main factors in developing kidney injury regarding type 2 diabetes [7]. Intrarenal RAAS activation by high glucose concentration leads to local angiotensin II overproduction in podocytes, mesangial cells and proximal tubular epithelial cells in type 2 diabetes producing inflammatory cytokines with progressive renal injury in the diabetic nephropathy $[8,9]$.

Chronic hyperglycemia inducing kidney injury occurs through the accumulation of advanced glycation end products (AGEs) in the kidney. The generation of AGEs in the kidney is linked to the development of diabetic nephropathy [10]. AGEs activate specific receptors, inducing cellular dysfunction and injury. An AGE-related functional defect in the permselective properties of the podocyte slit membrane may contribute to the development of albuminuria [11]. The activity of the enzyme, protein kinase $\mathrm{C}$, has been reported to be increased in various diabetic tissues including the glomerulus. Finally, hyperglycemia-induced oxidative stress and inflammation are mediators of kidney injury in type 2 diabetes [12]. Restoration of the mitochondrial structure, function, and signaling may be novel ways to improve diabetic nephropathy and prevent the decline in organ function.

SGLT2 Inhibitor and Kidney

\section{Genetic Factors}

A family history of nephropathy and hypertension is associated with a higher incidence of diabetic nephropathy. Diabetic nephropathy is a classic complex trait, whose development in a given individual likely reflects contributions from multiple genes. Several studies have noted an association between susceptibility genes including angiotensin-converting enzyme, angiotensin II (Ang II) receptor, various aspects of glucose metabolism, lipid metabolism (apolipoprotein E gene polymorphism), extracellular matrix, and inflammatory cytokines with diabetic nephropathy based on the pathogenic role in the development of disease [13, 14]. Genome-wide linkage analysis has identified several novel risk loci including SLC12A3 [15], ELMO1 [16], and SAM and SH3 domain containing 1 (SASH1) gene [17]. Currently, researchers continue to seek replicable genetic polymorphisms that confer diabetic nephropathy risk.

\section{Glycemic Control and Nephropathy}

Blood glucose control reduces the risk of developing microvascular complications. It could partially reverse glomerular hyperfiltration and decrease the incidence of new-onset microalbuminuria in retrospective [18] and prospective studies of patients with diabetes [19]. The main studies in new-onset type 1 and 2 diabetic patients including the Diabetes Control and Complications Trial (DCCT) [20], the Kumamoto study [21], and UK Prospective Diabetes Study (UKPDS) [22] have also indicated that intensified glycemic control delays the onset and slows the progression of albuminuria and nephropathy. Recently, the Epidemiology of Diabetes Interventions and Complications (EDIC) study has reported that longterm intensive glucose control in type 1 diabetes for 12 years decreased the incidence of impaired glomerular filtration rate (GFR) by $50 \%$ compared with those treated with conventional therapy [23]. Similarly, the UKPDS study reported that long-term intensive glucose control in patients with type 2 diabetes for 10 years continued to provide risk reduction for myocardial infarction and death from any cause [24]. It indicated that early and long-term glycemic control significantly ameliorates all complications including diabetic nephropathy. Moreover, the diabetic renal pathology, especially nodular glomerulosclerosis lesions, can be reversed with long-term glycemic control following pancreas transplantation in patients with type 1 diabetes $[25,26]$.

Kidney Dis 2017;3:24-32

DOI: $10.1159 / 000471765$ 
Table 1. Hypoglycemic agents in diabetes patients with CKD

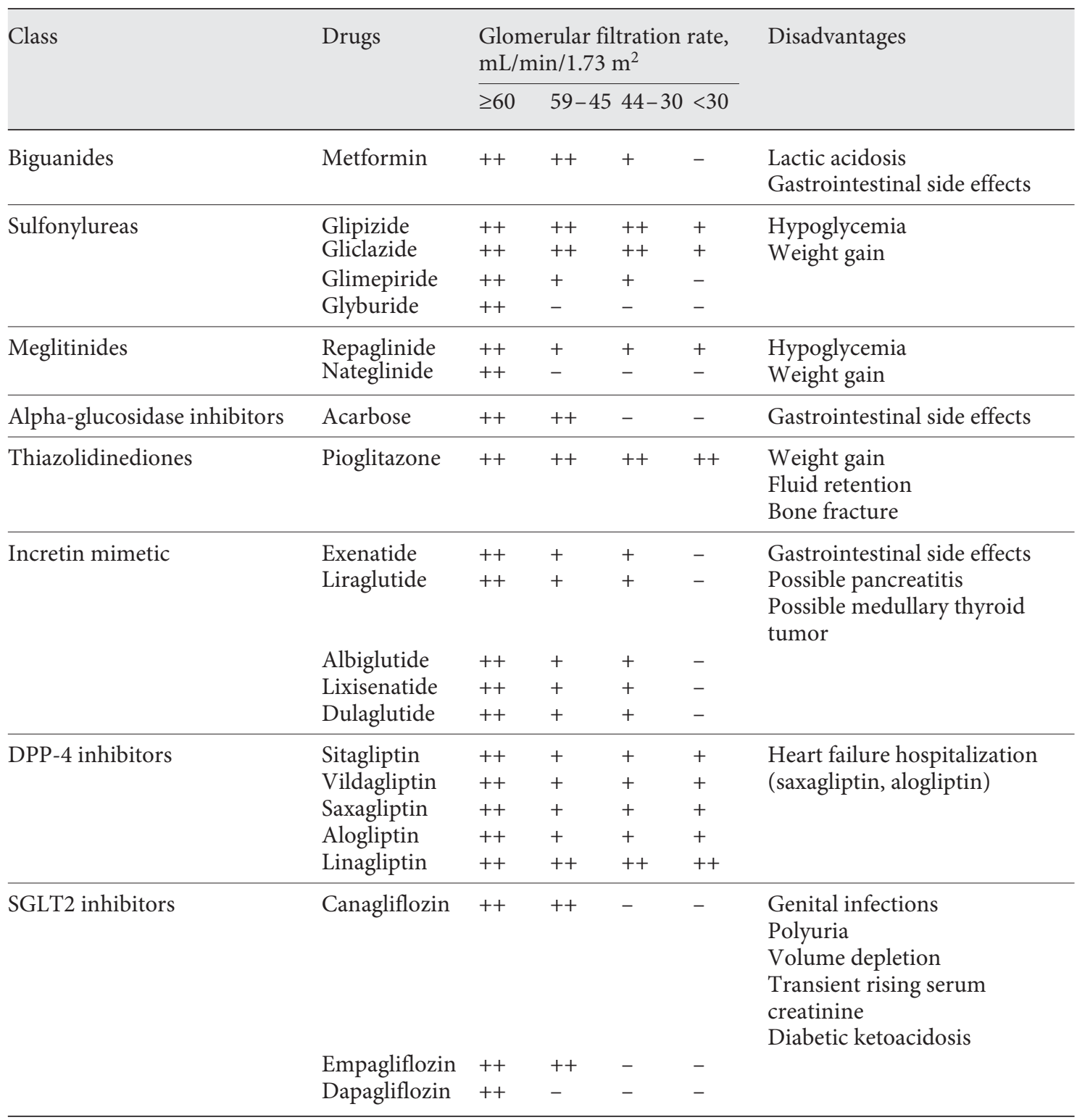

++, no dose adjustment; +, adjusted dose by $50 \%$; -, avoid use.

Major studies of long duration of type 2 diabetes including ACCORD, ADVANCE, and the VADT found that targeting even lower hemoglobin A1C (HbA1C) goals $(<6-6.5 \%)$ retarded the new onset of microalbuminuria, but failed to show cardiovascular disease risk reduction [27-29] and in the ACCORD trial, tight glycemic control was associated with a $22 \%$ increase in mortality from any cause [30]. A systematic review indicated that intensive glucose control reduced the risk for albumin- uria, but evidence is lacking that intensive glycemic control reduces the risk for ESRD [31].

The Kidney Disease Outcomes Quality Initiative (KDOQI) updated 2012 guidelines recommended lowering $\mathrm{HbA} 1 \mathrm{C}$ to below or around $7 \%$ for diabetes and chronic kidney disease (CKD) patients [32], and that this be implemented soon after the diagnosis of diabetes. Lowering $\mathrm{HbA1C}$ in these patients is associated with longterm reduction in macrovascular disease. However, these 
recommendations are not strongly evidence based, because limited studies addressed the benefits and risks of intensive glycemic control in advanced stages of kidney disease $[33,34]$. Less stringent HbA1C goals (such as $<8 \%$ ) are preferred among patients with a history of severe hypoglycemia, limited life expectancy, high comorbid conditions, longstanding diabetes, and advanced vascular complications, including advanced diabetic nephropathy. Glucose-lowering treatment and medications are based on the comfort of the patient and physician and must be individualized among patients with diabetic nephropathy. Patients with CKD are at increased risk of hypoglycemia due to decreased insulin clearance and hypoglycemic medications used to treat diabetes as well as reduce renal gluconeogenesis from CKD. Impaired renal function is associated with a prolonged insulin half-life and a decrease in insulin requirements and many hypoglycemic agents. The common hypoglycemic agents are excreted by the kidney, requiring dosage adjustment in CKD (Table 1).

Therapeutic options have increased substantially over the last decade, but the role of intensified glycemic control in patients with persistent microalbuminuria or overt nephropathy remains controversial. In addition, intensified glycemic control has not yet been translated into a remarkable reduction in the incidence of ESRD from diabetic nephropathy. Innovative strategies for glycemic control are needed to prevent renal complications. Promising clinical data suggest that sodium-glucose cotransporter 2 (SGLT2) inhibitors and glucagon-like-1 peptide agonists attenuate nephropathy independent of their glucose-lowering effects.

\section{SGLT2 Inhibitors}

The glucose filtered by the kidney is reabsorbed at a rate of approximately $180 \mathrm{~g} /$ day by the proximal tubules through SGLTs. The major glucose reabsorption is primarily handled by SGLT2 (up to 97\%), and SGLT2-specific inhibitors reducing the maximum renal glucose-reabsorptive capacity and threshold used to treat patients with type 2 diabetes block approximately $50 \%$ of the total glucose reabsorption [35]. A maladaptive mechanism contributing to hyperglycemia in type 2 diabetes comprises an increased expression and activity of SGLT2 for glucose reabsorption [36, 37].

SGLT2 inhibitors are a newly developed class of oral antidiabetic agents with a unique mechanism of action that is indicated only for the treatment in patients with

SGLT2 Inhibitor and Kidney type 2 diabetes. SGLT2 inhibitors improve glucose control by preventing reabsorption of glucose and increasing urinary glucose excretion. The mechanism of action of SGLT2 inhibitors also offers further glucose control by allowing increased insulin sensitivity and uptake of glucose in the muscle cells, decreased gluconeogenesis, and improved first-phase insulin release from the beta cells. These agents are efficacious as monotherapy and add-on therapy for patients with type 2 diabetes uncontrolled on metformin, sulfonylureas, pioglitazone, insulin, and other antihyperglycemic combinations.

Clinical studies with SGLT2 inhibitors have shown reduced $\mathrm{HbA1C}$ levels (0.7-0.9\%) without stimulating insulin secretion, and therefore without increasing the risk of hypoglycemia [38, 39]. Several studies indicated that SGLT2 inhibitors are used particularly in place of an insulin-providing agent or lower insulin dose requirement. The efficacy of SGLT2 inhibitors depends on the GFR and on plasma glucose levels. Among patients with eGFR $<60$ $\mathrm{mL} / \mathrm{min} / 1.73 \mathrm{~m}^{2}$ taking dapagliflozin, and patients with eGFR $<45 \mathrm{~mL} / \mathrm{min} / 1.73 \mathrm{~m}^{2}$ taking empagliflozin and canagliflozin, glycemic control was not improved compared with placebo [40-42]. In type 2 diabetes, these agents provide modest weight loss of up to $5 \mathrm{~kg}$ through urine glucose loss and systolic blood pressure reduction of up to $5 \mathrm{~mm} \mathrm{Hg}$, presumably through natriuretic effects. The SGLT2 inhibitor has been associated with a $10-15 \%$ reduction in plasma uric acid levels as a result of increased glycosuria, leading to the secretion of uric acid in exchange for glucose reabsorption through the GLUT9 transporter [39, 43], and serum uric acid-lowering effect of SGLT2 inhibition might improve endothelial dysfunction, hypertension, and microvascular injury in diabetes $[44,45]$.

\section{SGLT2 Inhibitors and Nephropathy}

SGLT2 inhibitors were effective in lowering albuminuria in patients with type 2 diabetes and hypertension using RAAS inhibition after adjusting for changes in HbA1C, blood pressure, body weight, and estimated GFR [46]. Overall, several clinical studies showed a significant reduction in albuminuria and a slow decline in GFR after SGLT2 inhibition initiation, and this lasted up to 2 years [46-48]. SGLT2 inhibition may lead to reduced longterm renal outcomes. A recent EMPA-REG OUTCOME study with a median follow-up of 3.1 years showed that in patients with high cardiovascular risk the SGLT2 inhibitor empagliflozin lowered the composite outcome of

Kidney Dis 2017;3:24-32 DOI: $10.1159 / 000471765$ 
Table 2. Potential mechanisms of renoprotection by SGLT2 inhibitors

\begin{tabular}{ll}
\hline Direct effects & Indirect effects \\
\hline $\begin{array}{l}\text { Renal hemodynamic effects } \\
\text { Reduced intraglomerular pressure by restoring tubuloglomerular } \\
\text { feedback }\end{array}$ & $\begin{array}{l}\text { Lower plasma glucose and HA1C } \\
\text { Lower serum uric acid } \\
\text { Lower blood pressure } \\
\text { Leduced albuminuria }\end{array}$ \\
$\begin{array}{l}\text { Reduced tubular } \mathrm{Na}^{+} \text {reabsorption } \\
\text { Reduced ANP levels }\end{array}$ & Lower body weight \\
$\begin{array}{l}\text { Renal nonhemodynamic effects } \\
\text { Reduced tubular glucotoxicity } \\
\text { Reduced AGE-mediated renal inflammation }\end{array}$ & \\
Reduced tubular apoptosis & \\
Reduced tubular excessive energy demands & \\
Reduced inflammatory mediators, and oxidative stress & \\
(MCP-1, ICAH-1, osteopontin, and TGF-beta) &
\end{tabular}

AGE, advanced glycation end product; ANP, atrial natriuretic peptides; ICAH-1, intracellular adhesion molecule-1; MCP-1, monocyte chemoattractant protein-1; RAAS, renin angiotensin aldosterone system; TGFbeta, transforming growth factor-beta.

myocardial infarction, stroke, and cardiovascular mortality by $14 \%$ (absolute rate 10.5 vs. $12.1 \%$ in the placebo group) and cardiovascular death by $38 \%$ (absolute rate 3.7 vs. 5.9\%) [49]. Additional outcomes were reported from recent meta-analyses that included 57 published trials; SGLT2 inhibitors protected against the risk of major adverse cardiovascular events (relative risk 0.84 [95\% CI $0.75-0.95])$ and death from any cause (0.71 [0.61-0.83]) [50]. For renal outcomes, patients receiving empagliflozin showed a $39 \%$ reduction in the risk of new or worsening nephropathy including macroalbuminuria, doubling of serum creatinine with GFR $<45 \mathrm{~mL} / \mathrm{min} / 1.73 \mathrm{~m}^{2}$, and initiation of renal replacement therapy [51]. These data strongly support that SGLT2 inhibitors have renoprotective properties not only by improving glycemic control but also through some direct renal effects as described below (Table 2).

\section{Renal Hemodynamic Effects}

SGLT2 inhibitors have the potential to exert renoprotection through hemodynamic effects. Accumulating evidence supports that increased single-nephron hyperfiltration is the major factor for kidney disease progression. Glomerular hyperfiltration in diabetic rats was associated with a reduction in distal sodium delivery flow by increased proximal tubular sodium-glucose reabsorption [52]. The limited sodium delivery flow and transport in- to the macula densa cells reduced ATP breakdown and adenosine generation in the juxtaglomerular apparatus. Decreased adenosine activation related to the lack tubuloglomerular feedback response causes vasodilation of the afferent arteriole and produces diabetic hyperfiltration and nephropathy [53]. Gene knockout of SGLT2 modestly lowered blood glucose in animal models of diabetes and prevented glomerular hyperfiltration [54]. SGLT2 inhibition treatment improves glomerular hyperfiltration with a reduction in GFR from $172 \pm 23$ to $139 \pm 25 \mathrm{~mL} /$ $\mathrm{min} / 1.73 \mathrm{~m}^{2}$ in type 1 diabetes [55]. Such a natriuretic effect increases sodium delivery to the distal tubule, thereby stimulating tubuloglomerular feedback, ultimately causing increased afferent renal arteriolar tone, attenuating glomerular pressure and reducing albuminuria.

Treatment with SGLT2 inhibitors resulted in an initial decrease in estimated GFR during the first 4 weeks with a progressive recovery of GFR during the following weeks, consistent with the mechanism of action involving decreased intraglomerular pressure [46-48]. These renal hemodynamic effects are similar to the effect of RAAS blockers for slow renal progression. RAAS inhibitors reduce intraglomerular pressure through efferent arteriolar vasodilatation, leading to reduced renal hyperfiltration. However, reduced glomerular pressure observed with SGLT2 inhibitors is mediated by blood pressure-independent pathways using afferent arteriolar vasoconstriction.
Satirapoj 
Indeed, in a recent experimental study, the combination of SGLT2 and RAAS inhibition showed more benefits in protecting kidney injury from glomerular hyperfiltration and proteinuria in animal models of advanced diabetic nephropathy [56]. Moreover, most patients with type 2 diabetes in the EMPA-REG OUTCOMES study were using a RAAS inhibitor at baseline, and the renal beneficial effects of treatment were confirmed in the subgroup of patients using an RAAS inhibitor [51]. The combination of RAAS and SGLT2 inhibition was associated with additive renoprotective effects in diabetic nephropathy compared with either drug alone.

Finally, intrarenal actions of atrial natriuretic peptides (ANP) contribute significantly to glomerular hyperfiltration in animal models of diabetes [57]. A modest reduction in effective circulating fluid volume with SGLT2 inhibitors decreases blood pressure and suppresses plasma ANP level in newly diagnosed type 2 diabetes [58]. These findings support the ability of SGLT2 inhibitors to lower ANP levels and improve glycemic control, which may benefit intraglomerular pressure and albuminuria.

\section{Renal Nonhemodynamic Effects}

All the renal cellular elements including the glomerular endothelium, mesangial cells, podocytes, and tubular epithelium are affected in the setting of chronic hyperglycemia. Furthermore, renal tubular compartments have been increasingly reported to play an integral role in the pathogenesis of diabetic nephropathy, and they correlate well with progressive renal function decline and represent a final common pathway of CKD [59]. Type 2 diabetes patients with high levels of urinary tubular biomarkers presented a more rapid decline in renal function. High levels of urinary tubular biomarkers were independent predictors of rapid renal progression among these patients [60]. Interestingly, SGLT2 inhibitors also have inhibitory effects on the inflammatory and fibrotic responses of proximal tubular cells to hyperglycemia. An in vitro study using human proximal tubular cells indicated that SGLT2 inhibitors augmented AGE-induced apoptotic cell death of tubular cells through RAGE induction [61] and decreased the high glucose-induced inflammatory and fibrotic markers by reducing glucose transport to the proximal tubule cells [62]. In animal models of type 2 diabetes, SGLT2 inhibitors decreased renal hypertrophy, renal inflammation, inflammatory mediators, and oxidative stress including monocyte chemoattractant protein-1, intracellular adhesion molecule-1, osteopontin,

SGLT2 Inhibitor and Kidney and transforming growth factor-beta, which are the main causes of diabetic nephropathy progression [63-65]. The benefits of SGLT2 inhibitors include attenuating renal glucose reabsorption in renal tubules and reducing proximal tubular glucotoxicity and glucose- and/or AGE-mediated renal inflammation.

High glucose and sodium reabsorption in the diabetic proximal tubules can increase oxygen consumption and glomerular hyperperfusion [66]. Recent evidence confirmed that chronic renal hypoxia initiated and promoted the microvascular injury and interstitial fibrosis that constituted the final common pathway to ESRD [67]. Thus, SGLT2 inhibitors reducing the excessive energy demands in the renal tubules might be a protective effect in diabetic nephropathy. In summary, in addition to glucoselowering effects, SGLT2 inhibitors might be a promising therapeutic approach to prevent diabetic nephropathy by renal hemodynamic and nonhemodynamic effects.

The American Diabetes Association (ADA) indicated that metformin is recommended as the standard first-line treatment for type 2 diabetes. When second hypoglycemic agents are required to achieved HA1C targets, the benefits and risks of adding sulfonylurea, thiazolidinedione, dipeptidyl peptidase 4 inhibitor, glucagon-like-1 peptide receptor agonist, SGLT2 inhibitor, or basal insulin are weighed in the context of an individual patient's preferences, as well as various patient, disease, and drug characteristics, with the goal of reducing blood glucose levels while minimizing side effects, especially hypoglycemia. The ADA recently added a new indication for empagliflozin, to reduce the risk of cardiovascular death among patients with longstanding suboptimally controlled type 2 diabetes and established atherosclerotic cardiovascular disease [68].

\section{Adverse Effects of SGLT2 Inhibitors}

SGLT2 inhibitors are associated with a low risk of hypoglycemia, but they may lead to adverse effects like genital fungal and urinary tract infections. A recent metaanalysis of clinical reports showed consistent increased risks of genital infections by approximately 3.0- to 5.0fold $[50,69]$. Another adverse event related to SGLT2 inhibitors involves intravascular volume depletion arising from the osmotic diuresis of glucose, and from natriuresis, and although infrequent, is more common among older adults and is related to the use of loop diuretics and tubular dysfunction [70]. After surveillance in the US, a warning was released by the Food and Drug Administra-

Kidney Dis 2017;3:24-32 DOI: $10.1159 / 000471765$ 
tion stating that several patients on SGLT2 inhibitors developed diabetic ketoacidosis. These adverse events occurred in patients with type 1 diabetes receiving off-label therapy against indication and type 2 diabetes with decreased insulin treatment because of concomitant SGLT2 inhibition.

In conclusion, glycemic control is essential to delay the onset of vascular complications from diabetes. Even the most experienced physician would find it challenging, but diabetic nephropathy remains the main cause of ESRD. Thus, new therapeutic strategies are needed to reduce this burden. SGLT2 inhibitors are a novel class of glucose-lowering agents with potential cardio- and renoprotective effects. SGLT2 inhibitors reduce blood pressure, body weight, intraglomerular pressure, albuminuria, and renal inflammatory, oxidative and fibrotic markers through mechanisms that appear independent of glycemia. According to an initial clinical study, this class of medications reduces renal events and dialysis in type 2 diabetes. Large long-term clinical trials are still needed to confirm the major renal benefits of SGLT2 inhibitors concerning the development and progression of diabetic nephropathy.

\section{Acknowledgement}

This work was supported in part by the National Science and Technology Development Agency (NSTDA, P-13-00505), Bangkok, Thailand.

\section{Conflict of Interest Statement}

The authors declare no conflicts of interest.

\section{References}

1 Satirapoj B, Adler SG: Comprehensive approach to diabetic nephropathy. Kidney Res Clin Pract 2014;33:121-131

2 Afkarian M, Sachs MC, Kestenbaum B, Hirsch IB, Tuttle KR, Himmelfarb J, de Boer IH: Kidney disease and increased mortality risk in type 2 diabetes. J Am Soc Nephrol 2013;24:302-308.

3 Satirapoj B: Review on pathophysiology and treatment of diabetic kidney disease. J Med Assoc Thai 2010;93(suppl 6):S228-S241.

4 Satirapoj B, Adler SG: Prevalence and management of diabetic nephropathy in western countries. Kidney Dis (Basel) 2015;1:61-70.

5 Mishra R, Emancipator SN, Kern T, Simonson MS: High glucose evokes an intrinsic proapoptotic signaling pathway in mesangial cells. Kidney Int 2005;67:82-93.

6 Heilig CW, Deb DK, Abdul A, Riaz H, James LR, Salameh J, Nahman NS Jr: GLUT1 regulation of the pro-sclerotic mediators of diabetic nephropathy. Am J Nephrol 2013;38:39-49.

7 Gurley SB, Coffman TM: The renin-angiotensin system and diabetic nephropathy. Semin Nephrol 2007;27:144-152.

8 Fan YY, Kobori H, Nakano D, Hitomi H, Mori H, Masaki T, Sun YX, Zhi N, Zhang L, Huang W, et al: Aberrant activation of the intrarenal renin-angiotensin system in the developing kidneys of type 2 diabetic rats. Horm Metab Res 2013;45:338-343.

9 Durvasula RV, Shankland SJ: Activation of a local renin angiotensin system in podocytes by glucose. Am J Physiol Renal Physiol 2008; 294:F830-F839.

10 Soulis T, Cooper ME, Vranes D, Bucala R, Jerums G: Effects of aminoguanidine in preventing experimental diabetic nephropathy are related to the duration of treatment. Kidney Int 1996;50:627-634.

11 Singh AK, Mo W, Dunea G, Arruda JA: Effect of glycated proteins on the matrix of glomerular epithelial cells. J Am Soc Nephrol 1998;9: 802-810.

12 Ha H, Hwang IA, Park JH, Lee HB: Role of reactive oxygen species in the pathogenesis of diabetic nephropathy. Diabetes Res Clin Pract 2008;82(suppl 1):S42-S45.

13 Freedman BI, Bostrom M, Daeihagh $\mathrm{P}$, Bowden DW: Genetic factors in diabetic nephropathy. Clin J Am Soc Nephrol 2007;2: 1306-1316.

14 Satirapoj B, Supasyndh O, Dispan R, Punpanich D, Tribanyatkul S, Choovichian P: Apolipoprotein E genetic polymorphisms and the development of nephropathy in type 2 diabetes. J Med Assoc Thai 2013;96:1119-1126.

15 Kim JH, Shin HD, Park BL, Moon MK, Cho YM, Hwang YH, Oh KW, Kim SY, Lee HK, Ahn C, et al: SLC12A3 (solute carrier family 12 member [sodium/chloride] 3) polymorphisms are associated with end-stage renal disease in diabetic nephropathy. Diabetes 2006;55:843-848.

16 Shimazaki A, Kawamura Y, Kanazawa A, Sekine A, Saito S, Tsunoda T, Koya D, Babazono T, Tanaka Y, Matsuda M, et al: Genetic variations in the gene encoding ELMO1 are associated with susceptibility to diabetic nephropathy. Diabetes 2005;54:1171-1178.

17 McDonough CW, Palmer ND, Hicks PJ, Roh $\mathrm{BH}$, An SS, Cooke JN, Hester JM, Wing MR, Bostrom MA, Rudock ME, et al: A genomewide association study for diabetic nephropathy genes in African Americans. Kidney Int 2011;79:563-572.
18 Kawazu S, Tomono S, Shimizu M, Kato N, Ohno T, Ishii C, Murata K, Watanabe T, Negishi K, Suzuki M, et al: The relationship between early diabetic nephropathy and control of plasma glucose in non-insulin-dependent diabetes mellitus. The effect of glycemic control on the development and progression of diabetic nephropathy in an 8-year followup study. J Diabetes Complications 1994;8: 13-17.

19 The Diabetes Control and Complications Trial Research Group: The effect of intensive treatment of diabetes on the development and progression of long-term complications in insulin-dependent diabetes mellitus. N Engl J Med 1993;329:977-986.

20 The Diabetes Control and Complications (DCCT) Research Group: Effect of intensive therapy on the development and progression of diabetic nephropathy in the Diabetes Control and Complications Trial. Kidney Int 1995;47:1703-1720.

21 Shichiri M, Kishikawa H, Ohkubo Y, Wake N: Long-term results of the Kumamoto Study on optimal diabetes control in type 2 diabetic patients. Diabetes Care 2000;23(suppl 2):B21B29.

22 Intensive blood-glucose control with sulphonylureas or insulin compared with conventional treatment and risk of complications in patients with type 2 diabetes (UKPDS 33). UK Prospective Diabetes Study (UKPDS) Group. Lancet 1998;352:837-853.

23 Group DER, de Boer IH, Sun W, Cleary PA, Lachin JM, Molitch ME, Steffes MW, Zinman $\mathrm{B}$ : Intensive diabetes therapy and glomerular filtration rate in type 1 diabetes. $N$ Engl J Med 2011;365:2366-2376. 
24 Holman RR, Paul SK, Bethel MA, Matthews DR, Neil HA: 10-year follow-up of intensive glucose control in type 2 diabetes. $\mathrm{N}$ Engl J Med 2008;359:1577-1589.

25 Fioretto P, Steffes MW, Sutherland DE, Goetz FC, Mauer M: Reversal of lesions of diabetic nephropathy after pancreas transplantation. N Engl J Med 1998;339:69-75.

26 Fioretto P, Sutherland DE, Najafian B, Mauer $\mathrm{M}$ : Remodeling of renal interstitial and tubular lesions in pancreas transplant recipients. Kidney Int 2006;69:907-912.

27 Gerstein HC, Miller ME, Byington RP, Goff DC Jr, Bigger JT, Buse JB, Cushman WC, Genuth S, Ismail-Beigi F, Grimm RH Jr, et al: Effects of intensive glucose lowering in type 2 diabetes. N Engl J Med 2008;358:2545-2559.

28 Patel A, MacMahon S, Chalmers J, Neal B, Billot L, Woodward M, Marre M, Cooper M, Glasziou P, Grobbee D, et al: Intensive blood glucose control and vascular outcomes in patients with type 2 diabetes. N Engl J Med 2008; 358:2560-2572.

29 Duckworth W, Abraira C, Moritz T, Reda D, Emanuele N, Reaven PD, Zieve FJ, Marks J, Davis SN, Hayward R, et al: Glucose control and vascular complications in veterans with type 2 diabetes. N Engl J Med 2009;360:129139.

30 Action to Control Cardiovascular Risk in Diabetes Study Group; Gerstein HC, Miller ME, Byington RP, Goff DC Jr, Bigger JT, Buse JB, Cushman WC, Genuth S, Ismail-Beigi F, et al: Effects of intensive glucose lowering in type 2 diabetes. N Engl J Med 2008;358:2545-2559.

31 Coca SG, Ismail-Beigi F, Haq N, Krumholz HM, Parikh CR: Role of intensive glucose control in development of renal end points in type 2 diabetes mellitus: systematic review and meta-analysis intensive glucose control in type 2 diabetes. Arch Intern Med 2012;172: 761-769.

32 National Kidney Foundation: KDOQI Clinical Practice Guideline for Diabetes and CKD: 2012 Update. Am J Kidney Dis 2012;60:850886.

33 Andrassy KM: Comments on "KDIGO 2012 clinical practice guideline for the evaluation and management of chronic kidney disease." Kidney Int 2013;84:622-623.

34 American Diabetes Association: Standards of medical care in diabetes - 2014. Diabetes Care 2014;37(suppl 1):S14-S80.

35 Gallo LA, Wright EM, Vallon V: Probing SGLT2 as a therapeutic target for diabetes: basic physiology and consequences. Diab Vasc Dis Res 2015;12:78-89.

36 DeFronzo RA, Hompesch M, Kasichayanula S, Liu X, Hong Y, Pfister M, Morrow LA, Leslie BR, Boulton DW, Ching A, et al: Characterization of renal glucose reabsorption in response to dapagliflozin in healthy subjects and subjects with type 2 diabetes. Diabetes Care 2013;36:3169-3176.
37 Rahmoune H, Thompson PW, Ward JM, Smith CD, Hong G, Brown J: Glucose transporters in human renal proximal tubular cells isolated from the urine of patients with noninsulin-dependent diabetes. Diabetes 2005; 54:3427-3434.

38 Leiter LA, Cefalu WT, de Bruin TW, GauseNilsson I, Sugg J, Parikh SJ: Dapagliflozin added to usual care in individuals with type 2 diabetes mellitus with preexisting cardiovascular disease: a 24-week, multicenter, randomized, double-blind, placebo-controlled study with a 28-week extension. J Am Geriatr Soc 2014;62:1252-1262.

39 Bailey CJ, Gross JL, Pieters A, Bastien A, List JF: Effect of dapagliflozin in patients with type 2 diabetes who have inadequate glycaemic control with metformin: a randomised, double-blind, placebo-controlled trial. Lancet 2010;375:2223-2233.

40 Kohan DE, Fioretto P, Tang W, List JF: Longterm study of patients with type 2 diabetes and moderate renal impairment shows that dapagliflozin reduces weight and blood pressure but does not improve glycemic control. Kidney Int 2014;85:962-971.

41 Yale JF, Bakris G, Cariou B, Nieto J, DavidNeto E, Yue D, Wajs E, Figueroa K, Jiang J, Law G, et al: Efficacy and safety of canagliflozin over 52 weeks in patients with type 2 diabetes mellitus and chronic kidney disease. Diabetes Obes Metab 2014;16:1016-1027.

42 Barnett AH, Mithal A, Manassie J, Jones R, Rattunde H, Woerle HJ, Broedl UC; EMPAREG RENAL trial investigators: Efficacy and safety of empagliflozin added to existing antidiabetes treatment in patients with type 2 diabetes and chronic kidney disease: a randomised, double-blind, placebo-controlled trial. Lancet Diabetes Endocrinol 2014;2:369384.

43 Lytvyn Y, Skrtic M, Yang GK, Yip PM, Perkins BA, Cherney DZ: Glycosuria-mediated urinary uric acid excretion in patients with uncomplicated type 1 diabetes mellitus. Am J Physiol Renal Physiol 2015;308:F77-F83.

44 Hovind P, Rossing P, Johnson RJ, Parving $\mathrm{HH}$ : Serum uric acid as a new player in the development of diabetic nephropathy. J Ren Nutr 2011;21:124-127.

45 Satirapoj B, Supasyndh O, Chaiprasert A, Ruangkanchanasetr P, Kanjanakul I, Phulsuksombuti D, Utainam D, Choovichian P: Relationship between serum uric acid levels with chronic kidney disease in a Southeast Asian population. Nephrology (Carlton) 2010;15: 253-258.

46 Heerspink HJ, Johnsson E, Gause-Nilsson I, Cain VA, Sjostrom CD: Dapagliflozin reduces albuminuria in patients with diabetes and hypertension receiving renin-angiotensin blockers. Diabetes Obes Metab 2016;18:590597.
47 Cherney D, Lund SS, Perkins BA, Groop PH, Cooper ME, Kaspers S, Pfarr E, Woerle HJ, von Eynatten M: The effect of sodium glucose cotransporter 2 inhibition with empagliflozin on microalbuminuria and macroalbuminuria in patients with type 2 diabetes. Diabetologia 2016;59:1860-1870.

48 Heerspink HJ, Desai M, Jardine M, Balis D, Meininger G, Perkovic V: Canagliflozin slows progression of renal function decline independently of glycemic effects. J Am Soc Nephrol 2017;28:368-375.

49 Zinman B, Wanner C, Lachin JM, Fitchett D, Bluhmki E, Hantel S, Mattheus M, Devins T, Johansen OE, Woerle HJ, et al: Empagliflozin, cardiovascular outcomes, and mortality in type 2 diabetes. N Engl J Med 2015;373:21172128.

$50 \mathrm{Wu} \mathrm{JH}$, Foote C, Blomster J, Toyama T, Perkovic V, Sundstrom J, Neal B: Effects of sodium-glucose cotransporter-2 inhibitors on cardiovascular events, death, and major safety outcomes in adults with type 2 diabetes: a systematic review and meta-analysis. Lancet Diabetes Endocrinol 2016;4:411-419.

51 Wanner C, Inzucchi SE, Lachin JM, Fitchett D, von Eynatten M, Mattheus M, Johansen OE, Woerle HJ, Broedl UC, Zinman B, et al: Empagliflozin and progression of kidney disease in type 2 diabetes. N Engl J Med 2016; 375:323-334.

52 Vallon V, Richter K, Blantz RC, Thomson S, Osswald H: Glomerular hyperfiltration in experimental diabetes mellitus: potential role of tubular reabsorption. J Am Soc Nephrol 1999; 10:2569-2576.

53 Faulhaber-Walter R, Chen L, Oppermann M, Kim SM, Huang Y, Hiramatsu N, Mizel D, Kajiyama H, Zerfas P, Briggs JP, et al: Lack of Al adenosine receptors augments diabetic hyperfiltration and glomerular injury. J Am Soc Nephrol 2008;19:722-730.

54 Vallon V, Rose M, Gerasimova M, Satriano J, Platt KA, Koepsell H, Cunard R, Sharma K, Thomson SC, Rieg T: Knockout of Na-glucose transporter SGLT2 attenuates hyperglycemia and glomerular hyperfiltration but not kidney growth or injury in diabetes mellitus. Am J Physiol Renal Physiol 2013;304:F156F167.

55 Cherney DZ, Perkins BA, Soleymanlou N, Maione M, Lai V, Lee A, Fagan NM, Woerle HJ, Johansen OE, Broedl UC, et al: Renal hemodynamic effect of sodium-glucose cotransporter 2 inhibition in patients with type 1 diabetes mellitus. Circulation 2014;129: 587-597.

56 Kojima N, Williams JM, Slaughter TN, Kato S, Takahashi T, Miyata N, Roman RJ: Renoprotective effects of combined SGLT2 and ACE inhibitor therapy in diabetic Dahl S rats. Physiol Rep 2015;3:e12436.

57 Zhang PL, Mackenzie HS, Troy JL, Brenner BM: Effects of an atrial natriuretic peptide receptor antagonist on glomerular hyperfiltration in diabetic rats. J Am Soc Nephrol 1994; 4:1564-1570. 
58 Wang Y, Xu L, Yuan L, Li D, Zhang Y, Zheng R, Liu C, Feng X, Li Q, Li Q, et al: Sodiumglucose co-transporter-2 inhibitors suppress atrial natriuretic peptide secretion in patients with newly diagnosed Type 2 diabetes. Diabet Med 2016;33:1732-1736.

59 Hills CE, Squires PE: The role of TGF-beta and epithelial-to mesenchymal transition in diabetic nephropathy. Cytokine Growth Factor Rev 2011;22:131-139.

60 Satirapoj B, Aramsaowapak K, Tangwonglert T, Supasyndh O: Novel tubular biomarkers predict renal progression in type 2 diabetes mellitus: a prospective cohort study. J Diabetes Res 2016;2016:3102962.

61 Maeda S, Matsui T, Takeuchi M, Yamagishi S: Sodium-glucose cotransporter 2-mediated oxidative stress augments advanced glycation end products-induced tubular cell apoptosis. Diabetes Metab Res Rev 2013;29: 406-412.

62 Panchapakesan U, Pegg K, Gross S, Komala MG, Mudaliar H, Forbes J, Pollock C, Mather
A: Effects of SGLT2 inhibition in human kidney proximal tubular cells - renoprotection in diabetic nephropathy? PLoS One 2013; 8:e54442.

63 Shin SJ, Chung S, Kim SJ, Lee EM, Yoo YH, Kim JW, Ahn YB, Kim ES, Moon SD, Kim MJ, et al: Effect of sodium-glucose co-transporter 2 inhibitor, dapagliflozin, on renal renin-angiotensin system in an animal model of type 2 diabetes. PLoS One 2016;11:e0165703.

64 Vallon V, Gerasimova M, Rose MA, Masuda T, Satriano J, Mayoux E, Koepsell H, Thomson SC, Rieg T: SGLT2 inhibitor empagliflozin reduces renal growth and albuminuria in proportion to hyperglycemia and prevents glomerular hyperfiltration in diabetic Akita mice. Am J Physiol Renal Physiol 2014; 306:F194-F204.

65 Terami N, Ogawa D, Tachibana H, Hatanaka T, Wada J, Nakatsuka A, Eguchi J, Horiguchi CS, Nishii N, Yamada H, et al: Long-term treatment with the sodium glucose cotransporter 2 inhibitor, dapagliflozin, ameliorates glucose homeostasis and diabetic nephropathy in $\mathrm{db} / \mathrm{db}$ mice. PLoS One 2014;9:e100777.

66 Korner A, Eklof AC, Celsi G, Aperia A: Increased renal metabolism in diabetes. Mechanism and functional implications. Diabetes 1994;43:629-633.

67 Fine LG, Norman JT: Chronic hypoxia as a mechanism of progression of chronic kidney diseases: from hypothesis to novel therapeutics. Kidney Int 2008;74:867-872.

68 Standards of Medical Care in Diabetes - 2017: Summary of Revisions. Diabetes Care 2017; 40:S4-S5.

69 Vasilakou D, Karagiannis T, Athanasiadou E, Mainou M, Liakos A, Bekiari E, Sarigianni M, Matthews DR, Tsapas A: Sodium-glucose cotransporter 2 inhibitors for type 2 diabetes: a systematic review and meta-analysis. Ann Intern Med 2013;159:262-274.

70 Nauck MA: Update on developments with SGLT2 inhibitors in the management of type 2 diabetes. Drug Des Devel Ther 2014;8: 1335-1380. 